\title{
Crizotinib induces apoptosis of lung cancer cells through JAK-STAT pathway
}

\author{
HONGMIN LU ${ }^{1 *}$, SHIBO WU ${ }^{2 *}$, HUAFEI CHEN ${ }^{3 *}$, YING HUANG ${ }^{4}$, \\ GUOQIN QIU ${ }^{5}$, LINGXIANG LIU ${ }^{6}$ and YONG LI ${ }^{7}$
}

\begin{abstract}
${ }^{1}$ Department of Medical Oncology, Renji Hospital Shanghai Jiaotong University School of Medicine, Shanghai 200000;
${ }^{2}$ Department of Respiratory Medicine, Li Huili Hospital, Ningbo Medical Center, Ningbo, Zhejiang 315041;

${ }^{3}$ Department of Thoracic Surgery, Zhejiang Rongjun Hospital, Jiaxing, Zhejiang 314001; ${ }^{4}$ Department of Respiratory Medicine,

The First Hospital Affiliated to AMU (Southwest Hospital), Chongqing 400038; ${ }^{5}$ Department of Thoracic Radiation Oncology, Zhejiang Cancer Hospital, Hangzhou, Zhejiang 310022; ${ }^{6}$ Department of Oncology, Jiangsu Province Hospital, Nanjing, Jiangsu 210029; ${ }^{7}$ Department of Thoracic Surgery, The Fourth Hospital of

Hebei Medical University, Shijiazhuang, Hebei 050011, P.R. China
\end{abstract}

Received March 9, 2018; Accepted August 17, 2018

DOI: $10.3892 / \mathrm{ol} .2018 .9387$

\begin{abstract}
Effect of crizotinib on apoptosis of lung cancer cells was investigated. Human non-small cell lung adenocarcinoma $\mathrm{H} 2228$ cells were cultured in the presence of $0,20,40,80$, 160 and $320 \mathrm{nmol} / \mathrm{l}$ of crizotinib for 3 days, respectively. The inhibition rate of cell proliferation was measured by MTT assay, and half maximal inhibitory concentration $\left(\mathrm{IC}_{50}\right)$ was calculated. Cell apoptosis was detected by flow cytometry. Transwell assay was performed to detect cell migration. Expression of Janus protein tyrosine kinase (JAK) and signal transducer and activator of transcription (STAT) proteins was detected by western blot analysis. Crizotinib significantly inhibited the proliferation of human lung cancer H2228 cells, and the inhibitory effect was enhanced with the increase of the concentration of crizotinib $(\mathrm{p}<0.01)$. The $\mathrm{IC}_{50}$ value was $311.26 \mathrm{nnol} / \mathrm{l}$. According to $\mathrm{IC}_{50}$ value, concentration of crizotinib at $300 \mathrm{nmol} / \mathrm{l}$ was selected for the study. It was found that crizotinib at $300 \mathrm{nmol} / 1$ significantly promoted cell apoptosis $(\mathrm{p}<0.01)$ and inhibited cell migration $(\mathrm{p}<0.01)$. Compared with pretreatment levels, crizotinib downregulated the expression
\end{abstract}

Correspondence to: Dr Lingxiang Liu, Department of Oncology, Jiangsu Province Hospital, 300 Guangzhou Road, Nanjing, Jiangsu 210029, P.R. China

E-mail: lingxiang12397@163.com

Dr Yong Li, Department of Thoracic Surgery, The Fourth Hospital of Hebei Medical University, 12 Jiankang Road, Shijiazhuang, Hebei 050011, P.R. China

E-mail: liyongdoctor@126.com

*Contributed equally

Key words: crizotinib, JAK-STAT signal, lung cancer, cell apoptosis, cell proliferation, cell migration of JAK and STAT $(\mathrm{p}<0.01)$ on the 1st day of treatment, but with the prolongation of time, no further significant difference was observed on the 1st, 2nd or 3rd day in the level of JAK protein $(\mathrm{p}=0.47)$; there were no statistically significant differences in the level of STAT protein $(\mathrm{p}=0.91)$. Crizotinib can inhibit the migration and promote cell apoptosis of human lung cancer cell line $\mathrm{H} 2228$ by regulating the expression of JAK and STAT proteins in JAK-STAT signaling pathway.

\section{Introduction}

Lung cancer is a genetic disease that is mainly caused by the activation of oncogenes (1), which can trigger abnormal cell proliferation and apoptosis, as well as the development of drug resistance in patients during treatment, leading to high mortality (2). Treatment outcomes of radiotherapy and chemotherapy are usually poor and adverse side effects are obvious. Therefore, molecular targeted therapy has attracted increased attention.

Janus protein tyrosine kinase (JAK) plays an important role in cell signaling (3). Activation of JAK can induce the phosphorylation of signal transducer and activator of transcription (STAT) to form JAK-STAT dimer, and the dimer will enter into the nucleus to induce expression of target genes, and this pathway is called the JAK-STAT signal pathway (4). STAT3 in the STAT family is involved in cell proliferation, differentiation, apoptosis, invasion and other cell activities (5). Activated STAT3 can activate some anti-apoptotic genes to prolong the cell cycle (6). Therefore, abnormalities of JAK-STAT pathway were often accompanied by the occurrence of tumors (7). Studies have shown that STAT3 in lung cancer is highly expressed (8). Crizotinib is an ATP mimetic and can act on multiple targets in the treatment of ALK or ROS1-positive lung cancer (9). The possible mechanism is related with the inhibition of ALK or c-MET phosphorylation, which in turn leads to the inhibition of cell proliferation (10). However, detailed mechanism is still unclear. Therefore, in 
this study, crizotinib was used to treat H2228 non-small cell lung adenocarcinoma cells and its effect was observed on cell apoptosis and expression of JAK and STAT protein, so as to explore the effects of crizotinib on lung cancer and the role of JAK-STAT signaling pathways.

\section{Materials and methods}

Main materials. Crizotinib powder was from Selleckchem Biotech, Inc. (Houston, TX, USA). 3-2,5-Diphenyl-2-Htetrazolium bromide (MTT) was purchased from Shanghai Solarbio Science \& Technology Co., Ltd. (Shanghai, China). RPMI-1640 medium and PBS were from Sigma-Aldrich (Merck KGaA, Darmstadt, Germany). RIPA lysate was purchased from Beyotime Institute of Biotechnology (Haimen, China). Cell apoptosis kit was from Solarbio. Transwell chamber was from Shanghai Yu Bo Biotechnology Co., Ltd. (Shanghai, China). Human non-small cell lung H2228 cell line was from Shanghai Cell Bank of Chinese Academy of Sciences (Shanghai, China). Gel imaging system was from Thermo Fisher Scientific, Inc., (Waltham, MA, USA) and microplate reader was provided by Bio-Rad Laboratories, Inc., (Hercules, CA, USA). The study was approved by the Ethics Committee of Renji Hospital Shanghai Jiaotong University School of Medicine (Shanghai, China). Patients who participated in this research, signed the informed consent and had complete clinical data.

Cell culture. H2228 lung cancer cells containing the EML4-ALK fusion gene were cultured in RPMI-1640 medium containing $10 \%$ fetal bovine serum at $37^{\circ} \mathrm{C}$ under $5 \% \mathrm{CO}_{2}$. The medium was changed twice a week, and cells are harvested at logarithmic growth phase for subsequent experiments.

MTT assay to detect cell inhibition rate. Cells were collected at logarithmic growth phase and inoculated into 96-well plates at a density of $1 \times 10^{7} / 1,200 \mu 1$ for each well. Cells were cultured at $37^{\circ} \mathrm{C}$ and $5 \% \mathrm{CO}_{2}$ for 2 days in incubator. After cell adhesion, 0 (control group), 20, 40, 80, 160 and $320 \mathrm{nmol} / 1$ (treatment groups) crizotinib was added to treat the cells. After incubation for 3 days at $37^{\circ} \mathrm{C}$ and $5 \% \mathrm{CO}_{2}$, liquid was discarded and $8 \mu \mathrm{l}$ MTT (5 g/l in PBS) was added to each well. After cell culture for another $4 \mathrm{~h}$, cell culture was terminated. After centrifugation at $1,800 \times \mathrm{g}$ for $5 \mathrm{~min}$ at $4^{\circ} \mathrm{C}$, culture supernatant was discarded, and $150 \mu \mathrm{l}$ DMSO was added to each well. The absorbance (A) of each well was detected by microplate reader, and the cell inhibition rate and $\mathrm{IC}_{50}$ value were calculated. Inhibition rate $(\%)=(1-\mathrm{A}$ value of treatment group/A value of control group) $\mathrm{x} 100 \%$.

Flow cytometry. Cells were harvested at logarithmic growth phase, and cell density was adjusted to $5 \times 10^{5} / \mathrm{ml}$. Then $1 \mathrm{ml}$ of cells was added into each well of 6-well plates. After cell adhesion, medium containing $300 \mathrm{nmol} / \mathrm{l}$ crizotinib was used to replace the original medium. After cell culture for 1,2 and 3 days, cells were collected and stained, followed by flow cytometry (FACSCalibur; BD Biosciences, Detroit, MI,USA), to measure cell apoptosis rate. This experiment was performed three times.
Table I. Inhibition rates of different concentrations of crizotinib on $\mathrm{H} 2228$ cell proliferation (mean $\pm \mathrm{SD}$ ).

\begin{tabular}{lc} 
Concentrations $(\mathrm{nmol} / \mathrm{l})$ & Inhibition rate $(\%)$ \\
\hline 0 & 0 \\
20 & $7.48 \pm 2.01$ \\
40 & $15.85 \pm 3.25$ \\
80 & $20.98 \pm 3.51$ \\
160 & $27.18 \pm 3.23$ \\
320 & $50.43 \pm 4.12$ \\
F-value & 72.91 \\
P-value & $<0.01$
\end{tabular}

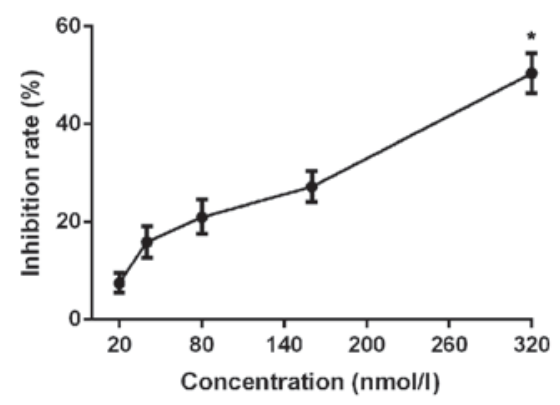

Figure 1. Inhibitory effect of crizotinib on cell proliferation of $\mathrm{H} 2228$ at different concentrations. Results of MTT showed that crizotinib significantly inhibited cell proliferation, and the inhibitory rate increased with the increase of crizotinib concentration ( $" \mathrm{p}<0.01)$

Transwell assay. Transwell chamber was placed in a 24-well culture plate, and a small amount serum-free medium was added into the upper chamber, followed by addition of Matrigel. The upper chamber was added with $400 \mu \mathrm{l}$ of cell suspension $\left(5 \times 10^{4}\right.$ cells $\left./ 1\right)$, while the lower chamber was filled with $500 \mu \mathrm{l}$ cell culture medium containing $10 \%$ fetal bovine serum. Cells were cultured under normal conditions, and 3 replicates were set for each experiment. After cell culture $24 \mathrm{~h}$, Transwell chambers were collected and fixed with formaldehyde, followed by staining with $0.1 \%$ crystal violet. Ten visual fields were randomly selected under a microscope to calculate the average number of cells that penetrated the membrane.

Western blot analysis to detect the expression of JAK and STAT proteins. RIPA solution was used to extract total protein from cells according to the instructions. Protein concentration was determined by BCA method. After blocking with $5 \%$ skimmed milk for $1 \mathrm{~h}$, membranes were incubated with primary antibodies overnight at $4^{\circ} \mathrm{C}$. After washing with TBST for $5 \mathrm{~min} \times 3$ times, membranes were incubated with secondary antibodies at room temperature for $1 \mathrm{~h}$. Primary rabbit polyclonal JAK antibody (1:500; cat. no. ab47435), mouse monoclonal STAT antibody (1:500; cat. no. AMAB90777), rabbit polyclonal GAPDH antibody (1:500; cat. no. ab37168) and secondary goat anti-rabbit (HRP) IgG antibody $(1: 2,000$; cat. no. ab6721) were all purchased from Abcam (Cambridge, MA, USA). Chemiluminescence method was used to detect 


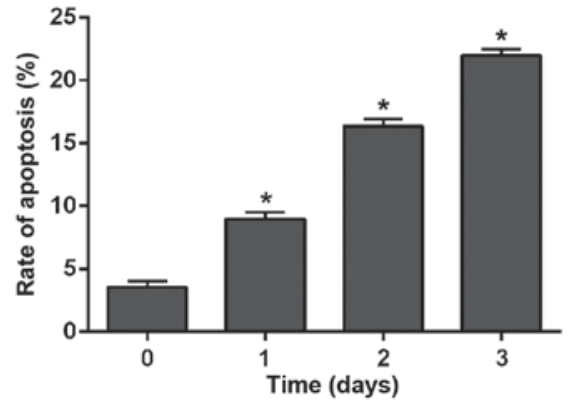

Figure 2. Effects of crizotinib on H2228 cell apoptosis. Flow cytometry results showed that crizotinib significantly promoted cell apoptosis, and with the passage of time, apoptotic rate was significantly increased ( $\mathrm{p} p<0.01)$.

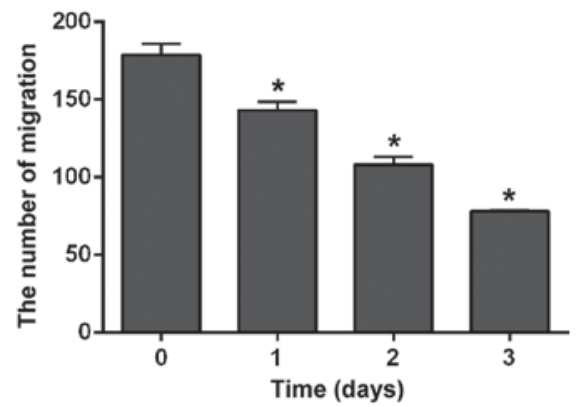

Figure 3. Effect of crizotinib on H2228 cell migration. Results of Transwell assay showed that crizotinib inhibited cell migration, and the inhibitory effect was enhanced with the prolongation of treatment $(" \mathrm{p}<0.01)$.

the signal, and signal was scanned by a gel imager (Thermo Fisher Scientific, Inc.).

Statistical analysis. Statistical analysis was performed by using SPSS 17.0 (SPSS, Inc., Chicago, IL, USA). Measurement data were expressed as mean \pm SD. Comparison between multiple groups was done using One-way ANOVA test followed by post hoc test (Least Significant Difference). t-test was used for comparison between two groups, and repeated measurements variance analysis was used for intragroup comparison. $\mathrm{P}<0.05$ was considered to indicate a statistically significant difference.

\section{Results}

Effects of crizotinib on H2228 cell proliferation. Cell proliferation was significantly inhibited after crizotinib treatment for 3 days, and the inhibitory rate increased with the increase of crizotinib concentration ( $\mathrm{p}<0.01$; Table I and Fig. 1$). \mathrm{IC}_{50}$ value was $311.26 \mathrm{nnol} / 1$ after administration for 3 days. Crizotinib at a concentration of $300 \mathrm{nmol} / \mathrm{l}$ was used in follow-up experiments.

Effects of crizotinib on H2228 cell apoptosis. $\mathrm{H} 2228$ cells were cultured in medium containing $300 \mathrm{nmol} / \mathrm{l}$ crizotinib. After cell culture for 1, 2 and 3 days, cells were detected by flow cytometry. As shown in Fig. 2, crizotinib obviously promoted cell apoptosis $(\mathrm{p}<0.01)$. With the prolongation of time, apoptotic rate of cells treated with crizotinib was significantly increased. The apoptotic rate at the 1st day was obviously higher than that

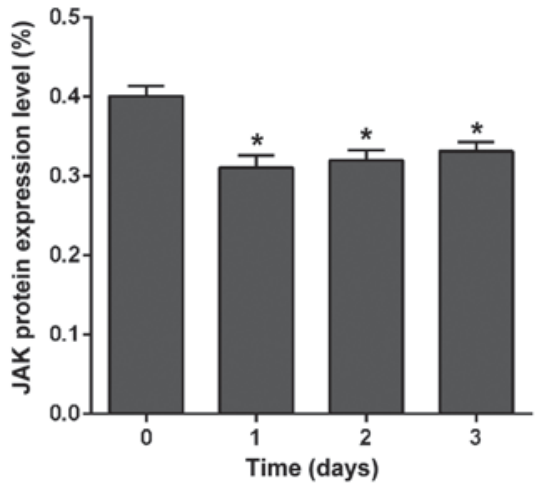

Figure 4. Effects of crizotinib on expression of JAK protein. Western blot analysis results showed that, compared with the level at $0 \mathrm{~h}$, crizotinib significantly inhibited JAK protein expression $\left({ }^{*} \mathrm{p}<0.01\right)$.

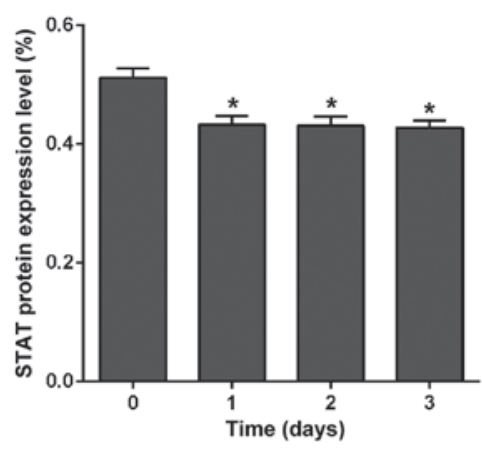

Figure 5. Effects of crizotinib on expression of STAT protein. Western blot analysis results showed that, compared with the level at $0 \mathrm{~h}$, crizotinib significantly inhibited STAT protein expression $\left({ }^{*} \mathrm{p}<0.01\right)$.

at 0 day $(\mathrm{F}=243.251, \mathrm{P}<0.01)$; apoptotic rate at the 2 nd day was obviously higher than that at the 1st day $(\mathrm{F}=279.783, \mathrm{P}<0.01)$ and apoptotic rate at the 3rd day was obviously higher than that at 2 nd day $(\mathrm{F}=167.524, \mathrm{P}<0.01)$.

Effects of crizotinib on H2228 cell migration. $\mathrm{H} 2228$ cells were cultured in medium containing $300 \mathrm{nmol} / \mathrm{l}$ crizotinib. Results of Transwell assay showed that the number of cells that infiltrated the membrane was significantly reduced with the prolonged treatment $(\mathrm{p}<0.01)$. The number of cells at the 1st day was obviously lower than that at 0 day $(\mathrm{F}=48.216$, $\mathrm{p}=0.002$ ); the number of cells at the 2 nd day was obviously lower than that at the 1 st day $(\mathrm{F}=68.398, \mathrm{p}=0.001)$ and the number of cells at the 3 rd day was obviously lower than that at the 2nd day ( $\mathrm{F}=53.912$, $\mathrm{p}=0.02)$ (Fig. 3).

Effects of crizotinib on expression of JAK and STAT proteins. Effect of crizotinib on the expression of JAK and STAT was detected by western blot analysis. Results showed that crizotinib significantly downregulated the expression of JAK protein after treatment for 1 day $(\mathrm{p}<0.01)$, but there was no significant difference at the 1st, 2nd, or 3rd day in the level of JAK protein ( $\mathrm{p}=0.47$ ) (Fig. 4). Crizotinib also significantly downregulated the expression of STAT protein after treatment for 1 day $(\mathrm{p}<0.01)$, but no significant difference was found either at the 1st, 2nd, or 3rd day in the level of STAT protein ( $\mathrm{p}=0.91$ ) (Fig. 5). 


\section{Discussion}

Apoptosis is an essential process in normal life, and abnormal apoptosis may trigger the occurrence of tumors (11). Inducing tumor cell apoptosis can effectively treat tumors (12). This study found that crizotinib can promote apoptosis and inhibit cell proliferation of cells of non-small cell lung adenocarcinoma cell line $\mathrm{H} 2228$, which is consistent with the findings reported by Anh et al (13), indicating the application value of crizotinib in the treatment of lung adenocarcinoma. Cell migration is cause of tumor metastasis and deaths of patients (14). In this study, results of Transwell assay showed that crizotinib can inhibit the migration of cancer cells in lung adenocarcinoma, which may be helpful for the treatment of lung cancer.

JAK-STAT signaling pathway is involved in cell growth, differentiation, immune and other functions, and abnormal JAK-STAT signaling can easily lead to the occurrence of tumors (15). Abnormal activation of JAK2 causes aberrant phosphorylation of STAT5, resulting in myeloproliferative tumors (16). Abnormal JAK2-STAT3 signaling and leukemia (17), and lymphoma (18) are closely related. Abnormal activation of STAT3 is also prevalent in lung cancer cells, and sustained high expression of STAT3 appears in early stage of non-small cell lung adenocarcinoma (19), and sustained activation of JAK-STAT3 signaling pathway can enhance tumor cell invasion and migration (20). In this study, results of western blot analysis showed that crizotinib significantly inhibited the expression of JAK and STAT proteins, indicating that crizotinib can promote apoptosis and inhibit the proliferation and migration of lung cancer cells. It can be seen that crizotinib might promote apoptosis and inhibit the proliferation and migration of lung cancer cells by inhibiting the expression level of JAK and STAT and inhibiting the activation of JAK-STAT signaling pathway, thus achieving the therapeutic effect of the treatment of lung cancer. This conclusion is consistent with the above theory. In addition, this study found that although crizotinib inhibited the expression of JAK and STAT, no increased inhibitory effects were observed after prolonged crizotinib treatment, indicating that long-term administration may not improve the condition further, possibly due to the development of drug resistance, which is a common problem in the treatment of lung cancer (21). This study only provides a theoretical basis for crizotinib in the treatment of lung cancer by regulating the JAK-STAT pathway. The resistance of crizotinib to lung cancer still needs to be further studied.

\section{Acknowledgements}

Not applicable.

\section{Funding}

No funding was received.

\section{Availability of data and materials}

The datasets used and/or analyzed during the present study are available from the corresponding author on reasonable request.

\section{Authors' contributions}

HL wrote the manuscript and helped with cell culture. SW and HC performed MTT assay. YH and GQ contributed to flow cytometry. LL and YL were responsible for Transwell assay and western blot analysis. All authors read and approved the final manuscript.

\section{Ethics approval and consent to participate}

The study was approved by the Ethics Committee of Renji Hospital Shanghai Jiaotong University School of Medicine (Shanghai, China). Patients who participated in this research, signed the informed consent and had complete clinical data.

\section{Patient consent for publication}

Not applicable.

\section{Competing interests}

The authors declare that they have no competing interests.

\section{References}

1. Watza D, Cote ML and Schwartz AG: Lung Cancer: genetics. In: eLS. John Wiley \& Sons, Ltd., Chichester, 2017.

2. Chen W, Zheng R, Baade PD, Zhang S, Zeng H, Bray F, Jemal A, $\mathrm{Yu}$ XQ and He J: Cancer statistics in China, 2015. CA Cancer J Clin 66: 115-132, 2016.

3. Wakeford R and Tawn EJ: Paternal irradiation and leukemia in offspring. Radiat Res 154: 222-223, 2000.

4. Pappa E, Nikitakis N, Vlachodimitropoulos D, Avgoustidis D Oktseloglou V and Papadogeorgakis N: Phosphorylated signal transducer and activator of transcription-1 immunohistochemical expression is associated with improved survival in patients with oral squamous cell carcinoma. J Oral Maxillofac Surg 72: 211-221, 2014.

5. Leeman RJ, Lui VW and Grandis JR: STAT3 as a therapeutic target in head and neck cancer. Expert Opin Biol Ther 6: 231-241, 2006.

6. Proietti C, Salatino M, Rosemblit C, Carnevale R, Pecci A, Kornblihtt AR, Molinolo AA, Frahm I, Charreau EH, Schillaci R, et al: Progestins induce transcriptional activation of signal transducer and activator of transcription 3 (Stat3) via a Jak- and Src-dependent mechanism in breast cancer cells. Mol Cell Biol 25: 4826-4840, 2005.

7. Gonçalves J and Silva AP: Methamphetamine and the JAK/STAT pathway. In: Neuropathology of Drug Addictions and Substance Misuse. Preedy VR (ed). Vol 2. 1st edition. Academic Press, Cambridge, MA, pp147-154, 2016.

8. Schütz A, Röser K, Klitzsch J, Lieder F, Aberger F, Gruber W, Mueller KM, Pupyshev A, Moriggl R and Friedrich K: Lung adenocarcinomas and lung cancer cell lines show association of MMP-1 expression with STAT3 activation. Trans Oncol 8: 97-105, 2015.

9. Puig de la Bellacasa R, Karachaliou N, Estrada-Tejedor R, Teixidó J, Costa C and Borrell JI: ALK and ROS1 as a joint target for the treatment of lung cancer: A review. Transl Lung Cancer Res 2: 72-86, 2013

10. Xu W, Kim JW, Jung WJ, Koh Y and Yoon SS: Crizotinib in combination with everolimus synergistically inhibits proliferation of ALK-positive anaplastic large cell lymphoma. Cancer Res Treat: Jun 19, 2017 (Epub ahead of print). https://doi. org/10.4143/crt.2016.357.

11. Adlakha YK and Saini N: MicroRNA: A connecting road between apoptosis and cholesterol metabolism. Tumour Biol 37: 8529-8554, 2016.

12. Han Y, Park S, Kinyua AW, Andera L, Kim KW and Kim I: Emetine enhances the tumor necrosis factor-related apoptosisinducing ligand-induced apoptosis of pancreatic cancer cells by downregulation of myeloid cell leukemia sequence-1 protein. Oncol Rep 31: 456-462, 2014. 
13. Ahn HK, Jeon K, Yoo H, Han B, Lee SJ, Park H, Lee MJ, Ha SY, Han JH, Sun JM, et al: Successful treatment with crizotinib in mechanically ventilated patients with ALK positive non-small-cell lung cancer. J Thorac Oncol 8: 250-253, 2013.

14. Roth W: Cell death in malignant tumors. Relevance of cell death regulation for metastasis. Pathologe 36 (Suppl 2): 181-184, 2015 (In German).

15. Song X, Zhang Z, Wang S, Li H, Zuo H, Xu X, Weng S, He J and Li C: A Janus Kinase in the JAK/STAT signaling pathway from Litopenaeus vannamei is involved in antiviral immune response. Fish Shellfish Immunol 44: 662-673, 2015.

16. Lee TS, Kantarjian H, Ma W, Yeh CH, Giles F and Albitar M: Effects of clinically relevant MPL mutations in the transmembrane domain revealed at the atomic level through computational modeling. PLoS One 6: e23396, 2011.

17. Rozovski U, Wu JY, Harris DM, Liu Z, Li P, Hazan-Halevy I, Ferrajoli A, Burger JA, O'Brien S, Jain N, et al: Stimulation of the B-cell receptor activates the JAK2/STAT3 signaling pathway in chronic lymphocytic leukemia cells. Blood 123: 3797-3802, 2014.
18. Jiang J, Liu Y, Tang Y, Li L, Zeng R, Zeng S and Zhong M: ALDH1A1 induces resistance to CHOP in diffuse large B-cell lymphoma through activation of the JAK2/STAT3 pathway. Onco Targets Ther 9: 5349-5360, 2016.

19. Jiang R, Wang X, Jin Z and Li K: Association of nuclear PIM expression with lymph node metastasis and poor prognosis in patients with lung adenocarcinoma and squamous cell carcinoma. J Cancer 7: 324-334, 2016.

20. Chu Q, Shen D, He L, Wang H, Liu C and Zhang W: Prognostic significance of SOCS3 and its biological function in colorectal cancer. Gene 627: 114-122, 2017.

21. Xue F, Zhu L, Meng QW, Wang L, Chen XS, Zhao YB, Xing Y, Wang XY and Cai L: FAT10 is associated with the malignancy and drug resistance of non-small-cell lung cancer. Onco Targets Ther 9: 4397-4409, 2016.

This work is licensed under a Creative Commons Attribution-NonCommercial-NoDerivatives 4.0 International (CC BY-NC-ND 4.0) License. 